\title{
Formation, Repair, and Genotoxic Properties of Bulky DNA Adducts Formed from Tobacco-Specific Nitrosamines
}

\author{
Lisa A. Peterson \\ Division of Environmental Health Sciences, Masonic Cancer Center, Mayo Mail Code 806, 420 Delaware St SE, \\ Minneapolis, MN 55455, USA \\ Correspondence should be addressed to Lisa A. Peterson, peter431@umn.edu
}

Received 7 June 2010; Accepted 8 July 2010

Academic Editor: Ashis Basu

Copyright ( $\odot 2010$ Lisa A. Peterson. This is an open access article distributed under the Creative Commons Attribution License, which permits unrestricted use, distribution, and reproduction in any medium, provided the original work is properly cited.

4-(Methylnitrosamino)-1-(3-pyridyl)-1-butanone (NNK) and $N^{\prime}$-nitrosonornicotine (NNN) are tobacco-specific nitrosamines present in tobacco products and smoke. Both compounds are carcinogenic in laboratory animals, generating tumors at sites comparable to those observed in smokers. These Group 1 human carcinogens are metabolized to reactive intermediates that alkylate DNA. This paper focuses on the DNA pyridyloxobutylation pathway which is common to both compounds. This DNA route generates 7-[4-(3-pyridyl)-4-oxobut-1-yl]-2' -deoxyguanosine, $O^{2}$-[4-(3-pyridyl)-4-oxobut-1-yl]-2'-deoxycytosine, $O^{2}$-[4(3-pyridyl)-4-oxobut-1-yl]-2'-deoxythymidine, and $\mathrm{O}^{6}$-[4-(3-pyridyl)-4-oxobut-1-yl]-2'-deoxyguanosine as well as unstable adducts which dealkylate to release 4-hydroxy-1-\{3-pyridyl)-1-butanone or depyriminidate/depurinate to generate abasic sites. There are multiple repair pathways responsible for protecting against the genotoxic effects of these adducts, including adduct reversal as well as base and nucleotide excision repair pathways. Data indicate that several DNA adducts contribute to the overall mutagenic properties of pyridyloxobutylating agents. Which adducts contribute to the carcinogenic properties of this pathway are likely to depend on the biochemistry of the target tissue.

\section{Introduction}

Tobacco use has been linked to a variety of human cancers, including lung, oral cavity, esophagus, pharynx, larynx, urinary bladder, pancreas, and liver cancers [1]. Lung cancer alone is responsible for the deaths of 1.3 million people annually worldwide [2]. It is the leading cause of cancer deaths in the United States, with $80 \%-90 \%$ of this cancer associated with tobacco use [1]. Environmental tobacco smoke (second-hand smoke) has also been associated with human lung cancer but the risks are significantly lower than those associated with smoking [1].

There are more than 5000 identified chemicals present in cigarette smoke [1,3-5]. More than 60 of these compounds are demonstrated chemical carcinogens in animal models [1, $3,4,6]$. An important group of tobacco carcinogens are the tobacco-specific nitrosamines. These compounds are formed from tobacco alkaloids like nicotine during the curing process of tobacco [7]. 4(Methylnitrosamino)-1-(3pyridyl)1-butanone $(\mathrm{NNK})$ and $N^{\prime}$-nitrosonornicotine $(\mathrm{NNN})$ are two of the most potent tobacco-specific nitrosamines present in tobacco products and smoke [8]. Both compounds are carcinogenic in laboratory animals, generating tumors at sites comparable to those observed in smokers [8]. NNK is a potent lung carcinogen, which also induces liver and nasal tumors [9-11]. This compound induces lung adenocarcinomas in rodents at lifetime doses that are comparable to those experienced by smokers [8]. Adenocarcinoma is now the most common type of lung cancer observed in humans, having surpassed squamous cell carcinoma [12-16]. This shift in histology has been attributed not to improvements in diagnoses but rather to changing cigarette design, which has changed smoking behavior resulting in increased uptake of tobacco-specific nitrosamines by smokers [14]. Metabolic products of NNK have been detected in urine of smokers and individuals exposed to second-hand smoke, indicating that humans are exposed to and metabolize this carcinogen [1720]. NNN is carcinogenic to the esophagus, nasal cavity, and respiratory tract in laboratory animals [8]. This nitrosamine is present in higher amounts than any other esophageal 
<smiles>CC(=O)OCN(CCCC(=O)c1cccnc1)N=O</smiles>

NNKOAc<smiles>CN(CCCC(=O)c1cccnc1)N=O</smiles>

NNK<smiles>CCCCC([N+]=O)c1cccnc1</smiles>

DNA adducts<smiles>NN(N)C1CC[As]C1c1cccnc1</smiles><smiles>O=NN(CO)CCCC(=O)c1cccnc1</smiles><smiles>CN(N=O)C(O)CCC(=O)c1cccnc1</smiles><smiles>O=NN1CCCC1(O)c1cccnc1</smiles>

DNA pyridyloxobutylation

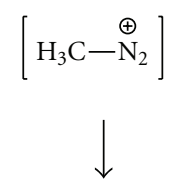

DNA methylation

Scheme 1: Pathways of bioactivation of NNK, NNN, and model pyridyloxobutylating agent, NNKOAc.

carcinogen in tobacco smoke [8]. It and/or its glucuronide conjugate have been detected in the urine and toenails of smokers and smokeless tobacco users [21-25]. Based on animal studies, NNK and NNN are listed as Group 1 human carcinogens by the International Agency for Cancer Research $[6,8]$.

NNK and NNN require metabolism to exert their toxicological properties [8]. NNK-induced carcinogenesis requires cytochrome P450 catalyzed metabolic activation to DNA reactive metabolites [26]. NNK is metabolized to either a methylating or a pyridyloxobutylating agent (Scheme 1). The methylation pathway generates well-characterized methyl DNA adducts, such as 7-methylguanine (7-mG), $O^{6}$ methylguanine $\left(\mathrm{O}^{6}-\mathrm{mG}\right)$, and $\mathrm{O}^{4}$-methylthymidine $\left(\mathrm{O}^{4}\right.$ $\mathrm{mT})$ [27-31]. The dominant mutagenic adduct is $O^{6}-\mathrm{mG}$ $[32,33]$. The repair mechanisms and genotoxic properties of this adduct have been extensively reviewed [34-37] and will not be a focus of this paper. The formation, repair, and genotoxic properties of the pyridyloxobutyl adducts will be discussed below.

NNN also has two pathways to form DNA adducts, $2^{\prime}$ - and $5^{\prime}$-hydroxylation [8]. (S)-NNN, the dominant enantiomer in tobacco products [38], undergoes primarily $2^{\prime}$-hydroxylation whereas $(R)$-NNN undergoes both $2^{\prime}$ and $5^{\prime}$-hydroxylation [39]. $2^{\prime}$-Hydroxylation generates the same pyridyloxobutylating agent as methyl hydroxylation of NNK (Scheme 1). 5'-Hydroxylation generates a reactive metabolite that can also alkylate DNA (Scheme 1) [40, 41]. However, no data exist for the levels of these adducts in vivo. For the purpose of this paper, we will focus on the pyridyloxobutylation pathway.

\section{Structure of Pyridyloxobutyl DNA Adducts}

The pyridyloxobutylation pathway leads to a variety of adducts, four of which have been recently identified (Scheme 2). They are 7-[4-(3-pyridyl)-4-oxobut-1-yl]-2'-deoxyguanosine (7-pobdG) [42], $\mathrm{O}^{2}$-[4-(3-pyridyl)-4-oxobut-1-yl]-2' deoxycytosine $\left(\mathrm{O}^{2}\right.$-pobdC) [43], $\mathrm{O}^{2}$-[4-(3-pyridyl)-4-oxobut-1-yl]-2'-deoxythymidine $\left(O^{2}\right.$-pobdT) [43], and $O^{6}$-[4(3-pyridyl)-4-oxobut-1-yl]-2'-deoxyguanosine $\left(\mathrm{O}^{6}\right.$-pobdG) [42-44]. Both 7-pobdG and $O^{2}$-pobdC readily release the corresponding nucleobases, 7[4-(3-pyridyl)-4-oxobut-1-yl]guanine (7-pobG) and $\mathrm{O}^{2}$-[4-(3-pyridyl)-4-oxobut-1-yl]cytosine $\left(\mathrm{O}^{2}\right.$-pobC), respectively, leaving behind an abasic site $[42,43]$. In addition, some pyridyloxobutyl DNA adducts are unstable and dealkylate to release 4-hydroxy-1(3-pyridyl)-1-butanone (HPB) (Scheme 2) [31, 45]. HPBreleasing adducts include $O^{2}$-pobdC [43] and 7-pobdG [42]. Quantitation of the specific pyridyloxobutyl DNA adducts in calf thymus DNA treated with a model pyridyloxobutylating agent, 4-(acetoxymethylnitrosamino)-1-(3-pyridyl)1-butanone (NNKOAc, Scheme 1), demonstrates that HPBreleasing adducts are the major adducts present in pyridyloxobutylated DNA [46]. They represent approximately $65 \%$ of the total adducts formed. The relative levels of the specific adducts making up the remainder are 7-pobG > $O^{6}$-pobdG $>O^{2}$-pobdT $\geq O^{2}$-pobC.

Conflicting evidence exists for the formation of phosphate adducts in pyridyloxobutylated DNA. HPB is not released from pyridyloxobutylated DNA when heated under basic conditions [45]. This observation is not consistent with the presence of pyridyloxobutyl phosphate esters. However, the $3^{\prime}$-termini of NNKOAc-induced strand breaks 
are resistant to ${ }^{32} \mathrm{P}$-endlabeling in the presence of T4 DNA polymerase even after incubating with endonuclease IV which removes $3^{\prime}$-phosphate or $3^{\prime}$-phosphoglycolate groups [47]. This observation suggests that there may be an adduct on the $3^{\prime}$ - phosphate group. However, the nucleobase adduct, $O^{6}$-pobdG, has been reported to inhibit $3^{\prime}$-exonuclease degradation of DNA [48]. Therefore, it is possible this adduct or other pyridyloxobutyl DNA adducts inhibits endonuclease IV as well. Also supporting the formation of pyridyloxobutyl phosphate adducts is the detection of a $4-\left(3-\left[5-{ }^{3} \mathrm{H}\right]\right.$ pyridyl $)$ 4-hydroxy-2-butylcobalam complex when enzymatic digests of DNA from $\left[5-{ }^{3} \mathrm{H}\right] \mathrm{NNK}$-treated animals were reacted with cob(I)alamin followed by sodium borohydride [49]. This reaction product accounted for up to $22 \%$ of the total pyridyloxobutyl adducts detected. Cob(I)alamin selectively reacts with alkyl phosphate adducts [50]. However, the pyridyloxobutyl group might be more reactive with this reagent than a simple alkyl group and the product may be formed from adducts other than alkyl phosphates. This possibility requires further testing.

\section{Levels of Pyridyloxobutyl DNA Adducts in NNK- or NNN-Treated Rodents}

Pyridyloxobutyl DNA adducts have been observed in DNA isolated from the tissues of NNK- or NNN-treated animals. HPB-releasing adducts have been detected in target tissues and have been shown to persist $[8,52]$. They have also been linked to tumor formation in the rat [53]. More recent studies have reported the levels of specific adducts in target and nontarget tissues of NNK- or NNN-treated rodents. One of the first studies demonstrated that $\mathrm{O}^{6}$ pobdG was present at very low levels in lung and liver DNA from $\left[5-{ }^{3} \mathrm{H}\right] \mathrm{NNK}$-treated A/J mice [54]. Subsequent experiments have employed sensitive LC-MS/MS assays [55, 56] for their detection of DNA from in vivo sources. Table 1 displays the levels of pyridyloxobutyl DNA adducts detected in lung and liver DNA following four subcutaneous doses of NNK [51]. In this study, the relative adduct distribution was $O^{2}$-pobdT $\geq 7$-pobG $>O^{2}$-pobC $\gg O^{6}$-pobdG in lung DNA and $O^{2}$-pobdT $=7$-pobG $\geq O^{2}$-pobC $\gg$ $O^{6}$-pobdG in liver DNA. The levels of 7-pobG, $O^{2}$-pobC and $O^{2}$-pobdT were higher in liver relative to lung DNA wherease the levels of $O^{6}$-pobdG were higher in lung relative to liver. $O^{2}$-pobdT was also the dominant adduct detected when rats were chronically treated with a lower dose of NNK (10 ppm in drinking water) (Table 2) $[57,58]$. The relative distribution of pyridyloxobutyl DNA adducts was $O^{2}$-pobdT $>7$-pobG $\gg O^{2}$-pobC $\gg O^{6}$-pobdG in lung DNA and $O^{2}$-pobdT $\gg 7$-pobG $>O^{2}$-pobC in liver DNA; $\mathrm{O}^{6}$-pobdG was not observed in liver DNA from these animals [57]. Pyridyloxobutyl DNA adducts were also observed in nasal respiratory mucosa, nasal olfactory mucosa, oral mucosa, and pancreas from NNK-treated rats [59]. The relative levels of total pyridyloxobutyl DNA adducts is lung > liver $>$ nasal respiratory mucosa $>$ nasal olfactory mucosa $\approx$ oral mucosa $\approx$ pancreas [59].

Similar studies have been performed in NNN-treated rats $[60,61]$. Chronic treatment of F344 rats with $(R)$ -<smiles></smiles>

7-pobdG<smiles>Nc1nc2ncn(CCCC(=O)c3cccnc3)c2c(=O)[nH]1</smiles>

7-pobG<smiles>CCCn1cc(C)c(=O)nc1OCCCC(=O)c1cccnc1</smiles>

$O^{2}$-pobdT<smiles></smiles>

$O^{2}$-pobdC<smiles>Nc1ccnc(OCCCC(=O)c2cccnc2)n1</smiles>

$O^{2}$-pobC<smiles>CCn1cnc2c(OCCCC(=O)c3cccnc3)nc(N)nc21</smiles>

$O^{6}$-pobdG<smiles>O=C(CCCO)c1cccnc1</smiles>

SCHEME 2: Structures of pyridyloxobutyl DNA adducts and HPB.

NNN or $(S)$-NNN in the drinking water $(10 \mathrm{ppm}, 1-$ 20 weeks) led to adduct formation in lungs, liver, nasal respiratory mucosa, nasal olfactory, and oral mucosa [60, 61]. Target tissues (nasal olfactory, respiratory mucosa, and esophagus) had the highest levels of pyridyloxobutyl DNA adducts whereas the nontarget tissues (lung and liver) had the lowest levels. The enantiomers gave different levels of pyridyloxobutyl DNA adducts in the various tissues. $(R)$ NNN produced the highest levels in lung nasal olfactory and nasal repiratory tissue whereas $(S)$-NNN generated higher levels in esophagus, liver, and oral mucosa $[60,61]$. These tissue-dependent differences are likely due to tissue differences in the cytochrome P450 enzymes responsible for the bioactivation of these two enantiomers $[60,61]$.

As with NNK, $O^{2}$-pobdT was a major adduct observed in DNA from various $\mathrm{NNN}$-exposed tissues such as nasal ofactory mucosa $\left(O^{2}\right.$-pobdT $>7$-pobG $\gg O^{2}$-pobC $>$ $O^{6}$-pobdG), respiratory mucosa $\left(O^{2}\right.$-pobdT $>7$-pobG $\gg$ $O^{2}$-pobC $>O^{6}$-pobdG $)$, and oral mucosa $\left(O^{2}\right.$-pobdT $\approx$ 7-pobG $\gg O^{2}$-pobC $>O^{6}$-pobdG) as well as liver and lung $\left(O^{2}\right.$-pobdT $\gg 7$-pobG $\geq O^{2}$-pobC). In the rat esophagus, 7-pobG was the dominant adduct (7-pobG $\geq O^{2}$-pobdT $\approx$ $O^{2}$-pobC). $O^{6}$-pobdG was not detected in lung, liver or esophageal DNA [60]. 
TABLE 1: Adduct levels in NNK-treated rats [51].

\begin{tabular}{|c|c|c|c|c|c|}
\hline \multirow[t]{2}{*}{ Tissue } & \multirow[t]{2}{*}{ NNK Dose $(\mathrm{mmol} / \mathrm{kg})^{\mathrm{a}}$} & 7-pobG & $O^{2}$-pobdT & $O^{2}-$ pobC & $O^{6}$-pobG \\
\hline & & \multicolumn{4}{|c|}{ Mean \pm S.D., $N=5(\mathrm{fmol} / \mathrm{mg}$ DNA $)$} \\
\hline \multirow{3}{*}{ Lung } & saline control & N.D. ${ }^{b}$ & N.D. & N.D. & N.D. \\
\hline & 0.025 & $933 \pm 89$ & $1120 \pm 66$ & $483 \pm 36$ & $251 \pm 26$ \\
\hline & 0.1 & $1800 \pm 478$ & $2020 \pm 483$ & $840 \pm 169$ & $487 \pm 101$ \\
\hline \multirow{3}{*}{ Liver } & saline control & N.D. & N.D. & N.D. & N.D. \\
\hline & 0.025 & $3550 \pm 1600$ & $3530 \pm 725$ & $2930 \pm 521$ & $28 \pm 17$ \\
\hline & 0.1 & $12200 \pm 1600$ & $12300 \pm 1690$ & $7800 \pm 1680$ & $140 \pm 25$ \\
\hline
\end{tabular}

${ }^{a}$ Administered by s.c. injection daily for 4 days.

${ }^{b}$ N.D.: not detected (detection limit, $3 \mathrm{fmol} / \mathrm{mg}$ DNA).

\section{Formation of Pyridyloxobutyl DNA Adducts in Humans}

While there is no information regarding the levels of the four individual pyridyloxobutyl DNA adducts in humans, HPB-releasing adducts have been detected in human tissue samples. Levels of these adducts were significantly higher $(P<.0001)$ in self-reported smokers who had lung cancer than in self-reported nonsmokers who had lung cancer ( $404 \pm 258$ versus $59 \pm 56 \mathrm{fmol} \mathrm{HPB} \mathrm{released} / \mathrm{mg}$ DNA, resp.) [62]. Since HPB-releasing adducts accumulate in normal lung tissues of lung cancer patients but not in normal smoking controls $[62,63]$, these data support a hypothesis that smokers who accumulate pyridyloxobutyl DNA adducts may be at increased risk of lung cancer.

\section{Repair Pathways for Pyridyloxobutyl DNA Adducts}

DNA adduct repair protects a cell against the toxic and genotoxic effects of DNA damage. There are multiple pathways involved in the removal of alkylated DNA bases generated by reactive alkanediazohydroxides. These include direct base repair by alkyltransferases and excision of the DNA damage by base excision repair (BER) or nucleotide excision repair (NER). Mismatch repair is involved in the detection and repair of mismatched DNA adducts. Below is a review of the pathways thought to be involved in the repair of pyridyloxobutyl DNA damage.

5.1. Adduct Reversal. $O^{6}$-Alkylguanine DNA alkyltransferase (AGT) is a suicide protein that repairs $O^{6}$-alkylguanine adducts by facilitating the transfer of the alkyl group from the $O^{6}$-position of guanine to a cysteine residue in the protein's active site [35]. This alkylation reaction inactivates the protein and triggers a conformational change [64] which leads to its degradation [65]. Consequently, the initial repair capacity of a cell is determined by its constitutive levels of AGT.

While $O^{6}$-pobdG is readily repaired by mammalian AGTs, it is not a good substrate for the bacterial AGTs ada and ogt [66]. The ability of AGT orthologs to repair this bulky $O^{6}$-alkylguanine adduct is likely determined by the size of the protein's adduct binding site. Rodent AGT has the largest binding site and repairs $O^{6}$-pobdG faster than human AGT which has a smaller binding pocket [66]. The bacterial AGTs have an even smaller binding pocket, explaining the inability of these proteins to repair this damage [66]. This adduct reversal pathway is a major repair pathway for $O^{6}$-pobdG in mammalian cells $[54,66,67]$.

5.2. Base Excision Repair. Base excision repair (BER) is another important pathway for the repair of nitrosaminederived DNA damage. This pathway is involved in the repair of single strand breaks, small alkyl guanine damage, and oxidized DNA bases as well as abasic sites [68, 69]. It is a multistep process that is initiated when damaged bases are removed by glycosylases, leaving abasic sites in DNA. The abasic sites are removed by an endonuclease. The missing nucleoside is then replaced and ligation occurs. It is likely that NNK-derived methyl adducts such as 7-methylguanine and $N^{3}$-methyladenine are removed by base excision repair [70]. The ability of pyridyloxobutyl adducts to serve as substrates for BER glycosylases has not been studied. It is possible that they could serve as substrates since the structurally similar adduct, $\mathrm{O}^{6}$-butylguanine, appears to be repaired in part by BER in vivo [71]. It is likely that abasic sites formed by the depurination/depyrimidination of 7-pobG and $\mathrm{O}^{2}$-pobC, respectively, are repaired by this pathway.

While little is known about the role of BER in the repair of pyridyloxobutyl DNA damage, two observations suggest that BER may be important. First, incubation of lysate from NNKOAc-treated cells with formamidopyrimidine glycosylase prior to the COMET assay results in a small but significant increase in strand breaks [72]. This observation indicates that there are pyridyloxobutyl DNA adducts that are substrates for this glycosylase. Second, loss of XRCC1, an important scaffold protein in BER [73], increases the mutagenic and toxic effects of NNKOAc [67]. The loss of this protein does not affect the rate of removal of specific pyridyloxobutyl DNA adducts from DNA [67]. However, the observed increase in toxicity and mutagenicity indicates 
TABle 2: Comparative DNA adduct levels in lung and liver of F344 rats treated with 10 ppm NNK in the drinking water and sacrificed at various intervals $[57,58]$.

\begin{tabular}{|c|c|c|c|c|c|c|c|}
\hline & \multicolumn{7}{|c|}{ Adduct Levels fmol/mg DNA (mean \pm S.D.) } \\
\hline \multirow{6}{*}{ Lung } & Week & 1 & 2 & 5 & 10 & 16 & 20 \\
\hline & $\mathrm{O}^{6}-\mathrm{mG}$ & $976 \pm 342$ & $1020 \pm 423$ & $2550 \pm 263$ & $1020 \pm 314$ & $729 \pm 57.5$ & $1910 \pm 615$ \\
\hline & $O^{6}$-pobdG & $45 \pm 7^{\mathrm{a}}$ & $50 \pm 5^{a}$ & $46 \pm 13^{\mathrm{a}}$ & $44 \pm 14^{\mathrm{a}}$ & $34 \pm 17^{\mathrm{a}}$ & $20 \pm 5^{\mathrm{a}}$ \\
\hline & 7-pobG & $750 \pm 95$ & $1180 \pm 131$ & $1360 \pm 214^{\mathrm{a}}$ & $2220 \pm 864$ & $1700 \pm 175^{\mathrm{a}}$ & $1060 \pm 169$ \\
\hline & $O^{2}$-pobdT & $1080 \pm 99$ & $2020 \pm 150$ & $3890 \pm 648$ & $8260 \pm 2730^{\mathrm{a}}$ & $6720 \pm 606^{\mathrm{a}}$ & $5070 \pm 1060^{\mathrm{a}}$ \\
\hline & $O^{2}$-pobC & $240 \pm 23$ & $250 \pm 18$ & $400 \pm 87^{\mathrm{a}}$ & $730 \pm 211$ & $810 \pm 152$ & $940 \pm 175$ \\
\hline \multirow{6}{*}{ Liver } & Week & 1 & 2 & 5 & 10 & 16 & 20 \\
\hline & $O^{6}-\mathrm{mG}$ & $3830 \pm 865$ & $7120 \pm 2080$ & $2310 \pm 946$ & $564 \pm 250$ & $637 \pm 59$ & $891 \pm 379$ \\
\hline & $O^{6}$-pobdG & n.d. & n.d. & n.d. & n.d. & n.d. & n.d. \\
\hline & 7-pobG & $490 \pm 104^{\mathrm{a}}$ & $880 \pm 182^{\mathrm{a}}$ & $1050 \pm 90$ & $1460 \pm 625$ & $1170 \pm 86^{\mathrm{a}}$ & $730 \pm 225$ \\
\hline & $O^{2}$-pobdT & $650 \pm 121^{\mathrm{a}}$ & $1230 \pm 272^{\mathrm{a}}$ & $2190 \pm 174$ & $3740 \pm 1170^{\mathrm{a}}$ & $3540 \pm 643^{a}$ & $2680 \pm 643^{a}$ \\
\hline & $O^{2}$-pobC & $170 \pm 43^{\mathrm{a}}$ & $140 \pm 25^{\mathrm{a}}$ & $240 \pm 17$ & $580 \pm 214$ & $350 \pm 152$ & $490 \pm 146$ \\
\hline
\end{tabular}

n.d., not detected.

a Significantly different from $O^{6}-\mathrm{mG}, P<.05$.

that XRCC1 plays an important role in protecting a cell against the harmful effects of these adducts. Together, these observations provide evidence for the role of BER in the repair of pyridyloxobutyl DNA damage.

5.3. Nucleotide Excision Repair. Another important pathway for the repair of bulky DNA damage is nucleotide excision repair (NER) $[74,75]$. Like BER, NER is a multiprotein mediated repair pathway. However, in this pathway a whole section of the damaged DNA strand is removed in several steps. A new strand is then synthesized by DNA polymerase using the undamaged strand as a template.

Several pieces of experimental data support the importance of NER in the repair of pyridyloxobutyl DNA adducts. In one study, $\left[\alpha_{-}{ }^{32} \mathrm{P}\right] \mathrm{TTP}$ was incorporated into NNKOActreated plasmid DNA when incubated with extracts from normal human lymphoid cells in an ATP-dependent fashion [76]. This activity was significantly lower in cell extracts from XPA- and XPC-deficient cell lines. XPA and XPC are two important proteins involved in the initiation of the NER pathway $[74,75]$ so their absence significantly impacts the efficiency of NER.

A second study examined the removal of specific pyridyloxobutyl DNA adducts from DNA in NNKOActreated Chinese hamster ovary cells [67]. The rate of removal of these adducts was compared between the parental cell line, AA8, which has functional NER but not AGT, and UV5 cells which lacks both functional NER [loss of ERCC-2 (XPD)] and AGT [77]. $O^{2}$-pobdT was the only adduct whose removal was affected by the loss of ERCC-2. Its repair was significantly slower in the absence of this protein, suggesting the importance of NER in the removal of this adduct. Since there were several reports indicating that larger
$O^{6}$-alkylguanine adducts appear to be preferentially repaired by nucleotide excision repair [78-82], $O^{6}$-pobdG repair was also expected to be reduced in cells lacking NER. However, $\mathrm{O}^{6}$-pobdG was a poor substrate for this pathway in $\mathrm{CHO}$ cells as well as in an in vitro human NER repair assay [67].

5.4. Mismatch Repair. Mismatch repair (MMR) is another important guard against genotoxic stress. In the case of alkylating agents, this pathway plays a critical role in the cytotoxicity mediated by these compounds [70, 83-85]. When alkylation is extensive, MMR is involved in triggering cell death which protects against the mutagenic activity of these agents. For example, MMR recognizes $O^{6}-\mathrm{mG}-$ $\mathrm{T}$ mismatch that occur when AGT is overwhelmed [83]. Unrepaired $O^{6}-\mathrm{mG}$ is toxic [36]; absence of MMR removes the toxicity of methylating agents indicating that this repair pathway is involved in the mechanism of toxicity [34]. MMR is initiated when the MSH2-MSH6 heterodimer ( $\mathrm{MutS} \alpha$ ) binds to the mismatch. The MLH1-PMS2 heterodimer then binds to MutS $\alpha$ and triggers removal of the mismatched base. In the case of damaged bases, the mismatch process enters a futile cycle if the adduct is not repaired since polymerases repeatedly insert the wrong base opposite the modified base. This futile cycle can trigger apoptosis $[70,85]$. This futile cycle can be thwarted by homologous recombination, a multiprotein pathway that uses the sister chromatid as the template to circumvent replication-halting DNA adducts $[85,86]$.

The role of mismatch repair in a cell's response to pyridyloxobutyl DNA adducts has not been explored. Preliminary data indicate that $O^{6}$-pobdG may not be a very toxic adduct. Repair of $O^{6}$-pobdG by human AGT in bacteria did not influence the toxicity of the model pyridyloxobutylating 
TABLE 3: Levels of $O^{6}$-mG and $O^{6}$-pobG in lung and livers of NNK-treated wild-type and AGT knockout mice ${ }^{\text {[88]. }}$

\begin{tabular}{|c|c|c|c|c|}
\hline \multirow{3}{*}{$\frac{\text { AGT status }}{O^{6}-\mathrm{mG}}$} & \multicolumn{4}{|c|}{ pmol adducts/ $\mu$ mol guanine } \\
\hline & \multicolumn{2}{|c|}{ lung } & \multicolumn{2}{|c|}{ liver } \\
\hline & $24 \mathrm{~h}$ & 4 weeks & $24 \mathrm{~h}$ & 4 weeks \\
\hline Wildtype & $42 \pm 12$ & $55 \pm 9$ & $17 \pm 11$ & $5.3 \pm 0.7$ \\
\hline Knockout & $65 \pm 19$ & $110 \pm 20$ & $210 \pm 110$ & $380 \pm 80^{\mathrm{b}}$ \\
\hline \multicolumn{5}{|l|}{$O^{6}-$ pobG } \\
\hline Wildtype & $1.7 \pm 0.5$ & $0.8 \pm 0.2$ & $1.4 \pm 0.5$ & $\leq 0.3$ \\
\hline Knockout & $2.9 \pm 0.6$ & $2.5 \pm 0.3$ & $2.7 \pm 1.2$ & $4.9 \pm 1.4$ \\
\hline
\end{tabular}

agent, NNKOAc [87]. This observation differs starkly from that observed with methylating agents where the toxicity of a methylating agent is markedly reduced when AGT is expressed [87]. Similar results were observed in CHO cells; AGT expression only minimally reduced the cytotoxicity of NNKOAc while repairing almost $100 \%$ of the $O^{6}$-pobdG formed by this pyridyloxobutylating agent [67]. The reduced toxicity of $O^{6}$-pobdG may cause it to more greatly contribute to the overall mutagenic activity of a pyridyloxobutylating agent since cell death protects against the mutagenic activity of DNA alkylating agents.

5.5. In Vivo Repair. For both NNK and NNN, the relative distribution of the four pyridyloxobutyl DNA adducts in tissues from exposed rats was significantly different from that observed in DNA treated with a model pyridyloxobutylating agent in vitro $[56,57,59-61]$. This difference likely results from the active repair of specific adducts. Further support for this hypothesis is the observed tissue variation in relative adduct distribution [57, 59-61].

One adduct that appears to be well-repaired in vivo is $O^{6}$-pobdG [56, 57, 59-61]. The levels of this adduct are very low relative to the other adducts (Tables 1 and 2). In NNK-treated animals, the levels of $\mathrm{O}^{6}-\mathrm{mG}$ were much greater than the levels of $O^{6}$-pobdG and in the range of the other pyridyloxobutyl DNA adducts [58]. This observation suggests that the larger adduct, $O^{6}$-pobdG, is more readily repaired than $O^{6} \mathrm{mG}$ in vivo. AGT is one pathway clearly responsible for the repair of $O^{6}$-pobdG in vivo [54]. However, other repair pathways may also be involved since this adduct does not accumulate in lungs of AGT knockout mice whereas $\mathrm{O}^{6}-\mathrm{mG}$ does (Table 3) [88]. This conclusion is further supported by data in wild-type mice which indicates that AGT is inactivated in mouse lung following exposure to NNK [89].

The most persistent adduct in vivo is $O^{2}$-pobdT $[56,57$, 59-61]. This adduct is a minor adduct in the absence of repair (7-pobG $>O^{6}$-pobdG $>O^{2}$-pobdT $\geq O^{2}$-pobC) [46]. This is somewhat surprising since this adduct is repaired by
NER in cell line models [67]. A recent study indicated that NER is reduced in the lungs of NNK-treated mice providing an explanation for the persistence of this adduct in vivo [90]. The mechanism of this reduction is unknown.

\section{Mutagenic Activity of Pyridyloxobutyl DNA Adducts}

Pyridyloxobutylating agents are mutagenic in a variety of test systems [67, 87, 91, 92]. However, our knowledge of which pyridyloxobutyl adducts are causing mutations is still rudimentary. Site-specific mutagenesis studies have only been performed for one adduct, $O^{6}$-pobdG [93]. In bacteria, it produces exclusively GC to AT transitional mutations. In human kidney cell line 293 cells, it produces primarily GC to AT transitional mutations with some GC to TA transversions and deletions as well as a number of more complex mutations.

A few studies have begun to link the overall mutagenic activity of pyridyloxobutyl DNA damage to specific adducts through exploring the impact of various DNA repair pathways on the mutagenic properties of the model pyridyloxobutylating agent, NNKOAc. The earliest studies were performed in bacteria. NNKOAc is mutagenic in Salmonella typhimurium tester strains TA100, TA1535, and TA98, but not TA102 [92]. Reversion of TA100 and TA1535 requires mutations at a GC base pair and reversion of TA98 requires a frameshift mutation near a CG base pair [94]. TA102 has an AT base pair at the site of reversion [94]. Based on these observations, it was concluded that pyridyloxobutyl DNA adducts formed at GC base pairs were mutagenic, at least in bacteria. However, we cannot rule out that adducts at AT base pairs are not mutagenic in this study since TA102 has an active NER system [94] that could be repairing any mutagenic adducts at AT base pairs. TA100, TA1535, and TA98 lack UvrB and, as a result, do not have an functional NER system [94].

One candidate adduct for the mutagenicity observed in TA100 and TA1535 is $O^{6}$-pobdG. This adduct is poorly 
repaired by bacterial AGT [66]. Consistent with its possible role in NNKOAc-induced mutagenicity is the observation that the mutagenic activity of NNKOAc was reduced by roughly $80 \%$ in bacteria expressing human AGT [87]. These studies were performed in S. typhimurium strain YG7108 which is a derivative of TA1535 that lacks both bacterial AGT genes, ada and ogt [95]. Since the levels of $O^{6}$-pobdG were reduced in the strain expressing human AGT by about $66 \%$ [87], these data are consistent with the hypothesis that $O^{6}$ pobdG is a significant contributor to the mutagenic activity of pyridyloxobutylating agents at GC base pairs. Other contributors may include $O^{2}$-pobC and 7-pobG. However, these two adducts are not substrates for human AGT.

NNKOAc also induced mutations in the hprt gene in Chinese hamster ovary (CHO) cells [67]. Analysis of the mutational spectrum indicated that the bulk of the mutations occurred at AT base pairs [67]. Most of the AT mutations were AT to CG transversion mutations. There were also a small portion of AT to TA transversions and AT to GC transitional mutations. Approximately $20 \%$ of the mutations were at GC base pairs with the majority of these being GC to AT transitional mutations.

Loss of NER through ERCC-2 mutation results in an increase in mutation frequency induced by NNKOAc in $\mathrm{CHO}$ cells [67]. This loss reduced the rate of $\mathrm{O}^{2}$-pobdT repair in these cells. In addition, there was a corresponding increase in the frequency of AT to TA mutations relative to the control cell line. Therefore, it is likely that $O^{2}$-pobdT triggers AT to TA mutations. This conclusion is supported by the observation that another $O^{2}$-alkyl-2' -deoxythymidine adduct, $O^{2}$-ethyl-2'-deoxythymidine, also induces AT to TA mutations [96]. Loss of BER through loss of XRCC1 also led to an increase in AT to TA mutations [67], suggesting that this repair pathway is involved in repair of pyridyloxobutyl DNA damage at AT base pairs. One possibility is that $O^{2}$ pobdT is a substrate for BER glycosylases and the result abasic sites are responsible for observed increase in AT to TA mutations observed in the cells lacking BER. This hypothesis is supported by the report that site-specifically incorporated abasic sites primarily induce transversion mutations with AT to TA mutations being more abundant than AT to GC mutations [97].

Expression of human AGT in $\mathrm{CHO}$ cells did not significantly impact the mutation frequency of NNKOAc [67]. However, mutations at GC base pairs represented only approximately $20 \%$ of the detected mutations. There was a reduction in the GC to AT mutations in these cells but this reduction did not significantly affect the mutation frequency. Since there was almost complete repair of $\mathrm{O}^{6}$ pobdG, these data support the hypothesis that $O^{6}$-pobdG is responsible for the GC to AT transitional mutations triggered by pyridyloxobutyl DNA adducts.

In vivo studies investigating the mutagenic properties of the pyridyloxobutylation pathway are limited. Mutations were observed in the 12th codon of K-ras in lung tumors of A/J mice receiving multiple doses of NNKOAc [98]. Since these mutations were GC to AT transitions and GC to TA transversions, it is likely that $O^{6}$-pobdG is responsible, in part, for these mutations. Both NNK and
$\mathrm{NNN}$ have been shown to be mutagenic in target tissues in lacZ and lacI transgenic mice $[88,99-101]$. The resulting transgene mutation spectra have only been reported for NNK $[88,101]$. NNK induced an increased rate of GC to AT transitional mutations at non-CpG sites as well as AT to TA transitional mutations and a mixture of transversion mutations (AT to GC, AT to CG, GC to CG, and GC to TA). Since NNK both methylates and pyridyloxobutylates DNA, it is difficult to associate specific mutations with specific adducts. However, it is clear that the mutational spectrum is substantially more complicated than that observed for simple methylating nitrosamines like dimethylnitrosamine, which primarily induces GC to AT transitional mutations at nonCpG sites [102-104].

Collectively, the data presented above indicate that there are several mutagenic DNA adducts formed upon pyridyloxobutylation of DNA. These include $O^{6}$-pobdG and $\mathrm{O}^{2}$-pobdT. Other adducts likely contribute as well. Which adducts contribute to the carcinogenic properties of this pathway are likely to depend on the biological system. If mutations at AT base pairs are required to produce proteins with oncogenic function, the formation of $O^{2}$-pobdT and its repair is probably important for tumor initiation by this pathway. On the other hand, if mutations at GC base pairs are important for triggering the carcinogenic process, the formation and persistence of $O^{6}$-pobdG will be linked to tumor formation. For example, GC to AT and GC to TA mutations were observed in the 12th codon of K-ras in lung tumors of $\mathrm{A} / \mathrm{J}$ mice receiving multiple doses of NNKOAc [98]. It is likely that $O^{6}$-pobdG is responsible, in part, for these mutations. Future studies are required to better define the toxicological properties of all pyridyloxobutyl adducts and to determine the repair pathways responsible for protecting against their genotoxic effects. An understanding of these fundamental biochemical issues may help in understanding the individual differences in susceptibility to lung cancer risk associated with tobacco use.

\section{Acknowledgment}

The research in the Peterson Laboratory has been funded by CA-59887 and CA-115309.

\section{References}

[1] International Agency for Research on Cancer, Tobacco Smoke and Involuntary Smoking, IARC, Lyon, France, 83rd edition, 2004.

[2] World Health Organization, "Cancer," Fact Sheet No. 297. 2009 http://www.who.int/mediacentre/factsheets/fs297/ en/print.html.

[3] D. Hoffmann and S. Hecht, "Advances in tobacco carcinogenesis," in Handbook of Experimental Pharmacology, C. S. Cooper and P. L. Grover, Eds., pp. 63-102, Springer, Berlin, Germany, 1990.

[4] G. N. Wogan, S. S. Hecht, J. S. Felton, A. H. Conney, and L. A. Loeb, "Environmental and chemical carcinogenesis," Seminars in Cancer Biology, vol. 14, no. 6, pp. 473-486, 2004.

[5] A. Rodgman and T. A. Perfetti, The Chemical Components of Tobacco and Tobacco Smoke, CRC Press, Boca Rotan, Fla, USA, 2009. 
[6] S. S. Hecht, "Tobacco smoke carcinogens and lung cancer," Journal of the National Cancer Institute, vol. 91, no. 14, pp. 1194-1210, 1999.

[7] S. S. Hecht and D. Hoffmann, "Tobacco-specific nitrosamines, an important group of carcinogens in tobacco and tobacco smoke," Carcinogenesis, vol. 9, no. 6, pp. 875-884, 1988.

[8] S. S. Hecht, "Biochemistry, biology, and carcinogenicity of tobacco-specific N-nitrosamines," Chemical Research in Toxicology, vol. 11, no. 6, pp. 559-603, 1998.

[9] S. S. Hecht, C. B. Chen, T. Ohmori, and D. Hoffmann, "Comparative carcinogenicity in F344 rats of the tobacco-specific nitrosamines, $N^{\prime}$-nitrosonornicotine and 4 - $(N$-methyl- $N$ nitrosamino)-1-(3-pyridyl)-1-butanone," Cancer Research, vol. 40, no. 2, pp. 298-302, 1980.

[10] A. Rivenson, D. Hoffmann, B. Prokopczyk, S. Amin, and S. S. Hecht, "Induction of lung and exocrine pancreas tumors in F344 rats by tobacco-specific and areca-derived $N$-nitrosamines," Cancer Research, vol. 48, no. 23, pp. 6912 6917, 1988.

[11] S. S. Hecht, M. A. Morse, S. Amin et al., "Rapid singledose model for lung tumor induction in $A / J$ mice by 4-(methylnitrosamino)-1-(3-pyridyl)-1-butanone and the effect of diet," Carcinogenesis, vol. 10, no. 10, pp. 1901-1904, 1989.

[12] S. S. Devesa, F. Bray, A. P. Vizcaino, and D. M. Parkin, "International lung cancer trends by histologic type: male:female differences diminishing and adenocarcinoma rates rising," International Journal of Cancer, vol. 117, no. 2, pp. 294-299, 2005.

[13] F. Chen, W. F. Bina, and P. Cole, "Declining incidence rate of lung adenocarcinoma in the United States," Chest, vol. 131, no. 4, pp. 1000-1005, 2007.

[14] M. J. Thun, C. A. Lally, J. T. Flannery, E. E. Calle, W. D. Flanders, and C. W. Heath Jr., "Cigarette smoking and changes in the histopathology of lung cancer," Journal of the National Cancer Institute, vol. 89, no. 21, pp. 1580-1586, 1997.

[15] D. Hoffmann, A. Rivenson, S. E. Murphy, F.-L. Chung, S. Amin, and S. S. Hecht, "Cigarette smoking and adenocarcinoma of the lung: the relevance of nicotine-derived $\mathrm{N}$ nitrosamines," Journal of Smoking-Related Disorders, vol. 4, no. 3, pp. 165-189, 1993.

[16] E. L. Wynder and D. Hoffmann, "Smoking and lung cancer: scientific challenges and opportunities," Cancer Research, vol. 54, no. 20, pp. 5284-5295, 1994.

[17] S. S. Hecht, S. G. Carmella, S. E. Murphy, S. Akerkar, K. D. Brunnemann, and D. Hoffmann, "A tobacco-specific lung carcinogen in the urine of men exposed to cigarette smoke," New England Journal of Medicine, vol. 329, no. 21, pp. 15431546, 1993.

[18] W. D. Parsons, S. G. Carmella, S. Akerkar, L. E. Bonilla, and S. S. Hecht, "A metabolite of the tobacco-specific lung carcinogen 4-(methylnitrosamino)-1-(3-pyridyl)-1-butanone in the urine of hospital workers exposed to environmental tobacco smoke," Cancer Epidemiology Biomarkers and Prevention, vol. 7, no. 3, pp. 257-260, 1998.

[19] G. M. Lackmann, U. Salzberger, U. Töllner, M. Chen, S. G. Carmella, and S. S. Hecht, "Metabolites of a tobacco-specific carcinogen in urine from newborns," Journal of the National Cancer Institute, vol. 91, no. 5, pp. 459-465, 1999.
[20] S. S. Hecht, "Carcinogen biomarkers for lung or oral cancer chemoprevention trials," IARC Scientific Publications, vol. 154, pp. 245-255, 2001.

[21] I. Stepanov and S. S. Hecht, "Tobacco-specific nitrosamines and their pyridine- $\mathrm{N}$-glucuronides in the urine of smokers and smokeless tobacco users," Cancer Epidemiology Biomarkers and Prevention, vol. 14, no. 4, pp. 885-891, 2005.

[22] I. Stepanov and S. S. Hecht, "Detection and quantitation of $N^{\prime}$-nitrosonornicotine in human toenails by liquid chromatography-electrospray ionization-tandem mass spectrometry," Cancer Epidemiology Biomarkers and Prevention, vol. 17, no. 4, pp. 945-948, 2008.

[23] I. Stepanov, S. G. Carmella, S. Han et al., "Evidence for endogenous formation of $N^{\prime}$-nitrosonornicotine in some long-term nicotine patch users," Nicotine and Tobacco Research, vol. 11, no. 1, pp. 99-105, 2009.

[24] D. Kavvadias, G. Scherer, M. Urban et al., "Simultaneous determination of four tobacco-specific $N$-nitrosamines (TSNA) in human urine," Journal of Chromatography B, vol. 877, no. 11-12, pp. 1185-1192, 2009.

[25] D. Kavvadias, G. Scherer, F. Cheung, G. Errington, J. Shepperd, and M. McEwan, "Determination of tobacco-specific $\mathrm{N}$-nitrosamines in urine of smokers and non-smokers," Biomarkers, vol. 14, no. 8, pp. 547-553, 2009.

[26] Y. Weng, C. Fang, R. J. Turesky, M. Behr, L. S. Kaminsky, and X. Ding, "Determination of the role of target tissue metabolism in lung carcinogenesis using conditional cytochrome P450 reductase-null mice," Cancer Research, vol. 67, no. 16, pp. 7825-7832, 2007.

[27] S. A. Belinsky, C. M. White, and J. A. Boucheron, "Accumulation and persistence of DNA adducts in respiratory tissue of rats following multiple administrations of the tobacco specific carcinogen 4-(N-methyl-N-nitrosamino)-1(3-pyridyl)-1-butanone," Cancer Research, vol. 46, no. 3, pp. 1280-1284, 1986.

[28] S. S. Hecht, N. Trushin, A. Castonguay, and A. Rivenson, "Comparative tumorigenicity and DNA methylation in F344 rats by 4-(methylnitrosamino)-1-(3-pyridyl)-1butanone and $N$-nitrosodimethylamine," Cancer Research, vol. 46, no. 2, pp. 498-502, 1986.

[29] S. A. Belinsky, J. F. Foley, C. M. White, M. W. Anderson, and R. R. Maronpot, "Dose-response relationship between $\mathrm{O}^{6}$-methylguanine formation in Clara cells and induction of pulmonary neoplasia in the rat by NNK," Cancer Research, vol. 50, no. 12, pp. 3772-3780, 1990.

[30] S. E. Murphy, A. Palomino, S. S. Hecht, and D. Hoffmann, "Dose-response study of DNA and hemoglobin adduct formation by 4-(methylnitrosamino)-1-(3-pyridyl)1-butanone in F344 rats," Cancer Research, vol. 50, no. 17, pp. 5446-5452, 1990.

[31] L. A. Peterson and S. S. Hecht, " $O^{6}$-Methylguanine is a critical determinant of 4-(methylnitrosamino)-1-(3-pyridyl)1-butanone tumorigenesis in A/J mouse lung," Cancer Research, vol. 51, no. 20, pp. 5557-5564, 1991.

[32] E. L. Loechler, C. L. Green, and J. M. Essigmann, "In vivo mutagenesis by $\mathrm{O}^{6}$-methylguanine built into a unique site in a viral genome," Proceedings of the National Academy of Sciences of the United States of America, vol. 81, pp. 62716275, 1984.

[33] R. E. Bishop, G. T. Pauly, and R. C. Moschel, " $O^{6}-$ Ethylguanine and $\mathrm{O}^{6}$-benzylguanine incorporated sitespecifically in codon 12 of the rat $\mathrm{H}$-ras gene induce semi-targeted as well as targeted mutations in Rat4 cells," Carcinogenesis, vol. 17, no. 4, pp. 849-856, 1996. 
[34] B. Kaina, M. Christmann, S. Naumann, and W. P. Roos, "MGMT: key node in the battle against genotoxicity, carcinogenicity and apoptosis induced by alkylating agents," DNA Repair, vol. 6, no. 8, pp. 1079-1099, 2007.

[35] A. E. Pegg, "Repair of $O^{6}$-alkylguanine by alkyltransferases," Mutation Research, vol. 462, no. 2-3, pp. 83-100, 2000.

[36] M. Bignami, M. O’Driscoll, G. Aquilina, and P. Karran, "Unmasking a killer: DNA $\mathrm{O}^{6}$-methylguanine and the cytotoxicity of methylating agents," Mutation Research, vol. 462, no. 2-3, pp. 71-82, 2000.

[37] P. F. Swann, "Why do $O^{6}$-alkylguanine and $O^{4}$-alkylthymine miscode? The relationship between the structure of DNA containing $\mathrm{O}^{6}$-alkylguanine and $\mathrm{O}^{4}$-alkylthymine and the mutagenic properties of these bases," Mutation Research, vol. 233, no. 1-2, pp. 81-94, 1990.

[38] S. G. Carmella, E. J. McIntee, M. Chen, and S. S. Hecht, "Enantiomeric composition of $N^{\prime}$-nitrosonornicotine and $N^{\prime}$-nitrosoanatabine in tobacco," Carcinogenesis, vol. 21, no. 4, pp. 839-843, 2000.

[39] E. J. McIntee and S. S. Hecht, "Metabolism of $N^{\prime}$-nitrosonornicotine enantiomers by cultured rat esophagus and in vivo in rats," Chemical Research in Toxicology, vol. 13, no. 3, pp. 192-199, 2000.

[40] P. Upadhyaya, E. J. McIntee, P. W. Villalta, and S. S. Hecht, "Identification of adducts formed in the reaction of $5^{\prime}$-acetoxy- $N^{\prime}$-nitrosonornicotine with deoxyguanosine and DNA," Chemical Research in Toxicology, vol. 19, no. 3, pp. 426-435, 2006.

[41] P. Upadhyaya and S. S. Hecht, "Identification of adducts formed in the reactions of $5^{\prime}$-acetoxy- $N^{\prime}$-nitrosonornicotine with deoxyadenosine, thymidine, and DNA," Chemical Research in Toxicology, vol. 21, no. 11, pp. 2164-2171, 2008.

[42] M. Wang, G. Cheng, S. J. Sturla et al., "Identification of adducts formed by pyridyloxobutylation of deoxyguanosine and DNA by 4-(acetoxymethylnitrosamino)-1-(3-pyridyl)1-butanone, a chemically activated form of tobacco specific carcinogens," Chemical Research in Toxicology, vol. 16, no. 5, pp. 616-626, 2003.

[43] S. S. Hecht, P. W. Villalta, S. J. Sturla et al., "Identification of $\mathrm{O}^{2}$-substituted pyrimidine adducts formed in reactions of 4-(Acetoxymethylnitrosamino)-1-(3-pyridyl)-1-butanone and 4-(Acetoxymethylnitrosamino)-1-(3-pyridyl)-1-butanol with DNA," Chemical Research in Toxicology, vol. 17, no. 5, pp. 588-597, 2004.

[44] L. Wang, T. E. Spratt, X.-K. Liu, S. S. Hecht, A. E. Pegg, and L. A. Peterson, "Pyridyloxobutyl adduct $O^{6}$-[4-oxo-4(3-pyridyl)butyl]guanine is present in 4-(acetoxymethylnitrosamino)-1-(3-pyridyl)-1-butanone-treated DNA and is a substrate for $O^{6}$-alkylguanine-DNA alkyltransferase," Chemical Research in Toxicology, vol. 10, no. 5, pp. 562-567, 1997.

[45] S. S. Hecht, T. E. Spratt, and N. Trushin, "Evidence for 4-(3pyridyl)-4-oxobutylation of DNA in F344 rats treated with the tobacco-specific nitrosamines 4-(methylnitrosamino)1-(3-pyridyl)-1-butanone and $N^{\prime}$-nitrosonornicotine," Carcinogenesis, vol. 9, no. 1, pp. 161-165, 1988.

[46] S. J. Sturla, J. Scott, Y. Lao, S. S. Hecht, and P. W. Villalta, "Mass spectrometric analysis of relative levels of pyridyloxobutylation adducts formed in the reaction of DNA with a chemically activated form of the tobaccospecific carcinogen 4-(methylnitrosamino)-1-(3-pyridyl)-1butanone," Chemical Research in Toxicology, vol. 18, no. 6, pp. 1048-1055, 2005.
[47] J.-F. Cloutier, R. Drouin, M. Weinfeld, T. R. O'Connor, and A. Castonguay, "Characterization and mapping of DNA damage induced by reactive metabolites of 4-(methylnitrosamino)1-(3-pyridyl)-1-butanone (NNK) at nucleotide resolution in human genomic DNA," Journal of Molecular Biology, vol. 313, no. 3, pp. 539-557, 2001.

[48] S. Park, M. Seetharaman, A. Ogdie, D. Ferguson, and N. Tretyakova, " 3 '-Exonuclease resistance of DNA oligodeoxynucleotides containing $\mathrm{O}^{6}$-[4-oxo-4-(3-pyridyl)butyl]guanine," Nucleic Acids Research, vol. 31, no. 7, pp. 1984-1994, 2003.

[49] J. Haglund, A. P. Henderson, B. T. Golding, and M. Törnqvist, "Evidence for phosphate adducts in DNA from mice treated with 4 -( $N$-methyl- $N$-nitrosamino)-1-(3pyridyl)-1-butanone (NNK)," Chemical Research in Toxicology, vol. 15, no. 6, pp. 773-779, 2002.

[50] J. Haglund, A. Rafiq, L. Ehrenberg, B. T. Golding, and M. Törnqvist, "Transalkylation of phosphotriesters using Cob(I)alamin: toward specific determination of DNAphosphate adducts," Chemical Research in Toxicology, vol. 13, no. 4, pp. 253-256, 2000.

[51] M. Wang, G. Cheng, P. W. Villalta, and S. S. Hecht, "Development of liquid chromatography electrospray ionization tandem mass spectrometry methods for analysis of DNA adducts of formaldehyde and their application to rats treated with N-nitrosodimethylamine or 4-(methylnitrosamino)-1(3-pyridyl)-1-butanone," Chemical Research in Toxicology, vol. 20, no. 8, pp. 1141-1148, 2007.

[52] S. S. Hecht, "DNA adduct formation from tobacco-specific $N$-nitrosamines," Mutation Research, vol. 424, no. 1-2, pp. 127-142, 1999.

[53] M. E. Staretz, P. G. Foiles, L. M. Miglietta, and S. S. Hecht, "Evidence for an important role of DNA pyridyloxobutylation in rat lung carcinogenesis by 4 -(methylnitrosamino)1-(3-pyridyl)-1-butanone: effects of dose and phenethyl isothiocyanate," Cancer Research, vol. 57, no. 2, pp. 259-266, 1997.

[54] N. M. Thomson, P. M. Kenney, and L. A. Peterson, "The pyridyloxobutyl DNA adduct, $O^{6}$-[4-oxo-4(3-pyridyl)butyl]guanine, is detected in tissues from 4(methylnitrosamino)-1-(3-pyridyl)-1-butanone-treated A/J mice," Chemical Research in Toxicology, vol. 16, no. 1, pp. 1-6, 2003.

[55] N. M. Thomson, R. S. Mijal, R. Ziegel et al., "Development of a quantitative liquid chromatography/electrospray mass spectrometric assay for a mutagenic tobacco specific nitrosamine-derived DNA adduct, $O^{6}$-[4-oxo-4-(3pyridyl)butyl]-2'-deoxyguanosine," Chemical Research in Toxicology, vol. 17, no. 12, pp. 1600-1606, 2004.

[56] Y. Lao, P. W. Villalta, S. J. Sturla, M. Wang, and S. S. Hecht, "Quantitation of pyridyloxobutyl DNA adducts of tobaccospecific nitrosamines in rat tissue DNA by high-performance liquid chromatography-electrospray ionization-tandem mass spectrometry," Chemical Research in Toxicology, vol. 19, no. 5, pp. 674-682, 2006.

[57] Y. Lao, N. Yu, F. Kassie, P. W. Villalta, and S. S. Hecht, "Formation and accumulation of pyridyloxobutyl DNA adducts in F344 rats chronically treated with 4-(methylnitrosamino)1-(3-pyridyl)-1-butanone and enantiomers of its metabolite, 4-(methylnitrosamino)-1-(3-pyridyl)-1-butanol," Chemical Research in Toxicology, vol. 20, no. 2, pp. 235-245, 2007.

[58] P. Upadhyaya, B. R. Lindgren, and S. S. Hecht, "Comparative levels of $\mathrm{O}^{6}$-methylguanine, pyridyloxobutyl-, and 
pyridylhydroxybutyl-DNA adducts in lung and liver of rats treated chronically with the tobacco-specific carcinogen 4-(methylnitrosamino)-1-(3-pyridyl)-1- butanone," Drug Metabolism and Disposition, vol. 37, no. 6, pp. 11471151, 2009.

[59] S. Zhang, M. Wang, P. W. Villalta et al., "Analysis of pyridyloxobutyl and pyridylhydroxybutyl DNA adducts in extrahepatic tissues of F344 rats treated chronically with 4-(methylnitrosamino)-1-(3-pyridyl)-1-butanone and enantiomers of 4-(methylnitrosamino)-1-(3-pyridyl)-1-butanol," Chemical Research in Toxicology, vol. 22, no. 5, pp. 926-936, 2009.

[60] Y. Lao, N. Yu, F. Kassie, P. W. Villalta, and S. S. Hecht, “Analysis of pyridyloxobutyl DNA adducts in F344 rats chronically treated with (R)- and (S)- $N^{\prime}$-nitrosonornicotine," Chemical Research in Toxicology, vol. 20, no. 2, pp. 246-256, 2007.

[61] S. Zhang, M. Wang, P. W. Villalta, B. R. Lindgren, Y. Lao, and S. S. Hecht, "Quantitation of pyridyloxobutyl DNA adducts in nasal and oral mucosa of rats treated chronically with enantiomers of $N^{\prime}$-nitrosonornicotine," Chemical Research in Toxicology, vol. 22, no. 5, pp. 949-956, 2009.

[62] D. Hölzle, D. Schlöbe, A. R. Tricker, and E. Richter, "Mass spectrometric analysis of 4-hydroxy-1-(3-pyridyl)-1butanone-releasing DNA adducts in human lung," Toxicology, vol. 232, no. 3, pp. 277-285, 2007.

[63] D. Schlöbe, D. Hölzle, D. Hatz, L. von Meyer, A. R. Tricker, and E. Richter, "4-Hydroxy-1-(3-pyridyl)-1butanone-releasing DNA adducts in lung, lower esophagus and cardia of sudden death victims," Toxicology, vol. 245, no. 1-2, pp. 154-161, 2008.

[64] D. S. Daniels, C. D. Mol, A. S. Arvai, S. Kanugula, A. E. Pegg, and J. A. Tainer, "Active and alkylated human AGT structures: a novel zinc site, inhibitor and extrahelical base binding," EMBO Journal, vol. 19, no. 7, pp. 1719-1730, 2000.

[65] M. Xu-Welliver and A. E. Pegg, "Degradation of the alkylated form of the DNA repair protein, $\mathrm{O}^{6}$-alkylguanine-DNA alkyltransferase," Carcinogenesis, vol. 23, no. 5, pp. 823-830, 2002.

[66] R. S. Mijal, N. M. Thomson, N. L. Fleischer et al., "The repair of the tobacco specific nitrosamine derived adduct $O^{6}$-[4-oxo-4-(3-pyridyl)butyl] guanine by $O^{6}$-alkylguanineDNA alkyltransferase variants," Chemical Research in Toxicology, vol. 17, no. 3, pp. 424-434, 2004.

[67] L. Li, J. Perdigao, A. E. Pegg et al., "The influence of repair pathways on the cytotoxicity and mutagenicity induced by the pyridyloxobutylation pathway of tobacco-specific nitrosamines," Chemical Research in Toxicology, vol. 22, no. 8, pp. 1464-1472, 2009.

[68] J. C. Fromme, A. Banerjee, and G. L. Verdine, "DNA glycosylase recognition and catalysis," Current Opinion in Structural Biology, vol. 14, no. 1, pp. 43-49, 2004.

[69] P. Fortini, B. Pascucci, E. Parlanti, M. D’Errico, V. Simonelli, and E. Dogliotti, "The base excision repair: mechanisms and its relevance for cancer susceptibility," Biochimie, vol. 85, no. 11, pp. 1053-1071, 2003.

[70] M. D. Wyatt and D. L. Pittman, "Methylating agents and DNA repair responses: methylated bases and sources of strand breaks," Chemical Research in Toxicology, vol. 19, no. 12, pp. 1580-1594, 2006.

[71] L. Airoldi, C. Magagnotti, M. Bonfanti et al., "Detection of $O^{6}$-butyl- and $O^{6}$-(4-hydroxybutyl)guanine in urothelial and hepatic DNA of rats given the bladder carcinogen $\mathrm{N}$ nitrosobutyl(4-hydroxybutyl)amine," Carcinogenesis, vol. 15, no. 10 , pp. 2297-2301, 1994.
[72] S. Lacoste, A. Castonguay, and R. Drouin, "Formamidopyrimidine adducts are detected using the comet assay in human cells treated with reactive metabolites of 4-(methylnitrosamino)-1-(3-pyridyl)-1-butanone (NNK)," Mutation Research, vol. 600, no. 1-2, pp. 138-149, 2006.

[73] J. Fan and D. M. Wilson III, "Protein-protein interactions and posttranslational modifications in mammalian base excision repair," Free Radical Biology and Medicine, vol. 38, no. 9, pp. 1121-1138, 2005.

[74] C. Petit and A. Sancar, "Nucleotide excision repair: from E. coli to man," Biochimie, vol. 81, no. 1-2, pp. 15-25, 1999.

[75] A. Sancar, L. A. Lindsey-Boltz, K. Ünsal-Kaçmaz, and S. Linn, "Molecular mechanisms of mammalian DNA repair and the DNA damage checkpoints," Annual Review of Biochemistry, vol. 73, pp. 39-85, 2004.

[76] P. J. Brown, L. L. Bedard, and T. E. Massey, "Repair of 4-(methylnitrosamino)-1-(3-pyridyl)-1-butanone-induced DNA pyridyloxobutylation by nucleotide excision repair," Cancer Letters, vol. 260, no. 1-2, pp. 48-55, 2008.

[77] L. H. Thompson, K. W. Brookman, and L. E. Dillehay, "Hypersensitivity to mutation and sister-chromatidexchange induction in $\mathrm{CHO}$ cell mutants defective in incising DNA containing UV lesions," Somatic Cell Genetics, vol. 8, no. 6, pp. 759-773, 1982.

[78] R. W. Chambers, E. Sledziewska-Gojska, S. Hirani-Hojatti, and $\mathrm{H}$. Borowy-Borowski, "uvrA and $\operatorname{rec} A$ mutations inhibit a site-specific transition produced by a single $O^{6}$ methylguanine in gene G of bacteriophage ФX174," Proceedings of the National Academy of Sciences of the United States of America, vol. 82, no. 21, pp. 7173-7177, 1985.

[79] R. W. Chambers, E. Sledziewska-Gojska, and S. HiraniHojatti, "In vivo effect of DNA repair on the transition frequency produced from a single $O^{6}$-methyl-or $O^{6}$-n-butylguanine in a T:G base pair," Molecular \& General Genetics, vol. 213, no. 2-3, pp. 325-331, 1988.

[80] S. A. M. Bol, H. van Steeg, C. T. H. M. van Oostrom et al., "Nucleotide excision repair modulates the cytotoxic and mutagenic effects of $N$-butyl- $N$-nitrosourea in cultured mammalian cells as well as in mouse splenocytes in vivo," Mutagenesis, vol. 14, no. 3, pp. 317-322, 1999.

[81] J. M. Boyle, R. Saffhill, G. P. Margison, and M. Fox, "A comparison of cell survival, mutation and persistence of putative promutagenic lesions in Chinese hamster cells exposed to BNU or MNU," Carcinogenesis, vol. 7, no. 12, pp. 1981-1985, 1986.

[82] J. M. Boyle, G. P. Margison, and R. Saffhill, "Evidence for the excision repair of $O^{6}$-n-butyldeoxyguanosine in human cells," Carcinogenesis, vol. 7, no. 12, pp. 1987-1990, 1986.

[83] D. R. Duckett, J. T. Drummond, A. I. H. Murchie, et al., "Human MutS $\alpha$ recognizes damaged DNA base pairs containing $\mathrm{O}^{6}$ methylguanine, $\mathrm{O}^{4}$-methylthymine, or the cisplatin $\mathrm{d}(\mathrm{GpG})$ adduct," Proceedings of the National Academy of Sciences of the United States of America, vol. 93, pp. 64436447, 1996.

[84] J. Wu, L. Gu, H. Wang, N. E. Geacintov, and G.-M. Li, "Mismatch repair processing of carcinogen-DNA adducts triggers apoptosis," Molecular and Cellular Biology, vol. 19, no. 12, pp. 8292-8301, 1999.

[85] M. Christmann, M. T. Tomicic, W. P. Roos, and B. Kaina, "Mechanisms of human DNA repair: an update," Toxicology, vol. 193, no. 1-2, pp. 3-34, 2003.

[86] J. H. J. Hoeijmakers, "Genome maintenance mechanisms for preventing cancer," Nature, vol. 411, no. 6835, pp. 366-374, 2001. 
[87] R. S. Mijal, N. A. Loktionova, C. C. Vu, A. E. Pegg, and L. A. Peterson, " $\mathrm{O}^{6}$-pyridyloxobutylguanine adducts contribute to the mutagenic properties of pyridyloxobutylating agents," Chemical Research in Toxicology, vol. 18, no. 10, pp. 16191625, 2005.

[88] L. E. Sandercock, J. N. Hahn, L. Li et al., "Mgmt deficiency alters the in vivo mutational spectrum of tissues exposed to the tobacco carcinogen 4-(methylnitrosamino)-1(3-pyridyl)-1-butanone (NNK)," Carcinogenesis, vol. 29, no. 4, pp. 866-874, 2008.

[89] L. A. Peterson, N. M. Thomson, D. L. Crankshaw, E. E. Donaldson, and P. J. Kenney, "Interactions between methylating and pyridyloxobutylating agents in $\mathrm{A} / \mathrm{J}$ mouse lungs: implications for 4-(methylnitrosamino)-1-(3-pyridyl)-1-butanoneinduced lung tumorigenesis," Cancer Research, vol. 61, no. 15, pp. 5757-5763, 2001.

[90] P. J. Brown and T. E. Massey, "In vivo treatment with 4(methylnitrosamino)-1-(3-pyridyl)-1-butanone (NNK) induces organ-specific alterations in in vitro repair of DNA pyridyloxobutylation," Mutation Research, vol. 663, no. 1-2, pp. 15-21, 2009.

[91] S. S. Hecht, D. Lin, and A. Castonguay, "Effects of $\alpha$ deuterium substitution on the mutagenicity of 4 -(methylnitrosamino)-1-(3-pyridyl)-1-butanone (NNK)," Carcinogenesis, vol. 4, no. 3, pp. 305-310, 1983.

[92] P. G. Foiles, L. A. Petersen, L. M. Miglietta, and Z. Ronai, "Analysis of mutagenic activity and ability to induce replication of polyoma DNA sequences by different model metabolites of the carcinogenic tobacco-specific nitrosamine 4(methylnitrosamino)-1-(3-pyridyl)-1-butanone," Mutation Research, vol. 279, no. 2, pp. 91-101, 1992.

[93] G. T. Pauly, L. A. Peterson, and R. C. Moschel, "Mutagenesis by $\mathrm{O}^{6}$-[4-oxo-4-(3-pyridyl)butyl]guanine in Escherichia coli and human cells," Chemical Research in Toxicology, vol. 15, no. 2, pp. 165-169, 2002.

[94] D. M. Maron and B. N. Ames, "Revised methods for the salmonella mutagenicity test," Mutation Research, vol. 113, no. 3-4, pp. 173-215, 1983.

[95] M. Yamada, B. Sedgwick, T. Sofuni, and T. Nohmi, "Construction and characterization of mutants of Salmonella typhimurium deficient in DNA repair of $O^{6}$-methylguanine," Journal of Bacteriology, vol. 177, no. 6, pp. 1511-1519, 1995.

[96] O. S. Bhanot, P. C. Grevatt, J. M. Donahue, C. N. Gabrielides, and J. J. Solomon, "In vitro DNA replication implicates O2-ethyldeoxythymidine in transversion mutagenesis by ethylating agents," Nucleic Acids Research, vol. 20, no. 3, pp. 587-594, 1992.

[97] V. Simonelli, L. Narciso, E. Dogliotti, and P. Fortini, "Base excision repair intermediates are mutagenic in mammalian cells," Nucleic Acids Research, vol. 33, no. 14, pp. 4404-4411, 2005.

[98] Z. A. Ronai, S. Gradia, L. A. Peterson, and S. S. Hecht, "G to A transitions and $\mathrm{G}$ to $\mathrm{T}$ transversions in codon 12 of the Ki-ras oncogene isolated from mouse lung tumors induced by 4(methylnitrosamino)-1-(3-pyridyl)-1-butanone (NNK) and related DNA methylating and pyridyloxobutylating agents," Carcinogenesis, vol. 14, no. 11, pp. 2419-2422, 1993.

[99] M. D. M. von Pressentin, W. Kosinska, and J. B. Guttenplan, "Mutagenesis induced by oral carcinogens in lacZ mouse (MutaMouse) tongue and other oral tissues," Carcinogenesis, vol. 20, no. 11, pp. 2167-2170, 1999.

[100] M. D. M. von Pressentin, M. Chen, and J. B. Guttenplan, "Mutagenesis induced by 4-(methylnitrosamino)-1-(3-pyridyl)-1-butanose-4-(methylnitrosamino)-1-(3-pyridyl)-1- butanone and $\mathrm{N}$-nitrosonornicotine in lacZ upper aerodigestive tissue and liver and inhibition by green tea," Carcinogenesis, vol. 22, no. 1, pp. 203-206, 2001.

[101] K. Hashimoto, K.-I. Ohsawa, and M. Kimura, "Mutations induced by 4-(methylnitrosamino)-1-(3-pyridyl)-1butanone (NNK) in the lacZ and cII genes of Muta Mouse," Mutation Research, vol. 560, no. 2, pp. 119-131, 2004.

[102] X. Wang, T. Suzuki, T. Itoh et al., "Specific mutational spectrum of dimethylnitrosamine in the lad transgene of big blue C57BL/6 mice," Mutagenesis, vol. 13, no. 6, pp. 625-630, 1998.

[103] V. L. Souliotis, J. H. M. van Delft, M.-J. S. T. Steenwinkel, R. A. Baan, and S. A. Kyrtopoulos, "DNA adducts, mutant frequencies and mutation spectra in $\lambda l a c Z$ transgenic mice treated with $\mathrm{N}$-nitrosodimethylamine," Carcinogenesis, vol. 19, no. 5, pp. 731-739, 1998.

[104] B. S. Shane, D. L. Smith-Dunn, J. G. de Boer, B. W. Glickman, and M. L. Cunningham, "Mutant frequencies and mutation spectra of dimethylnitrosamine (DMN) at the lacI and cII loci in the livers of Big Blue transgenic mice," Mutation Research, vol. 452, no. 2, pp. 197-210, 2000. 

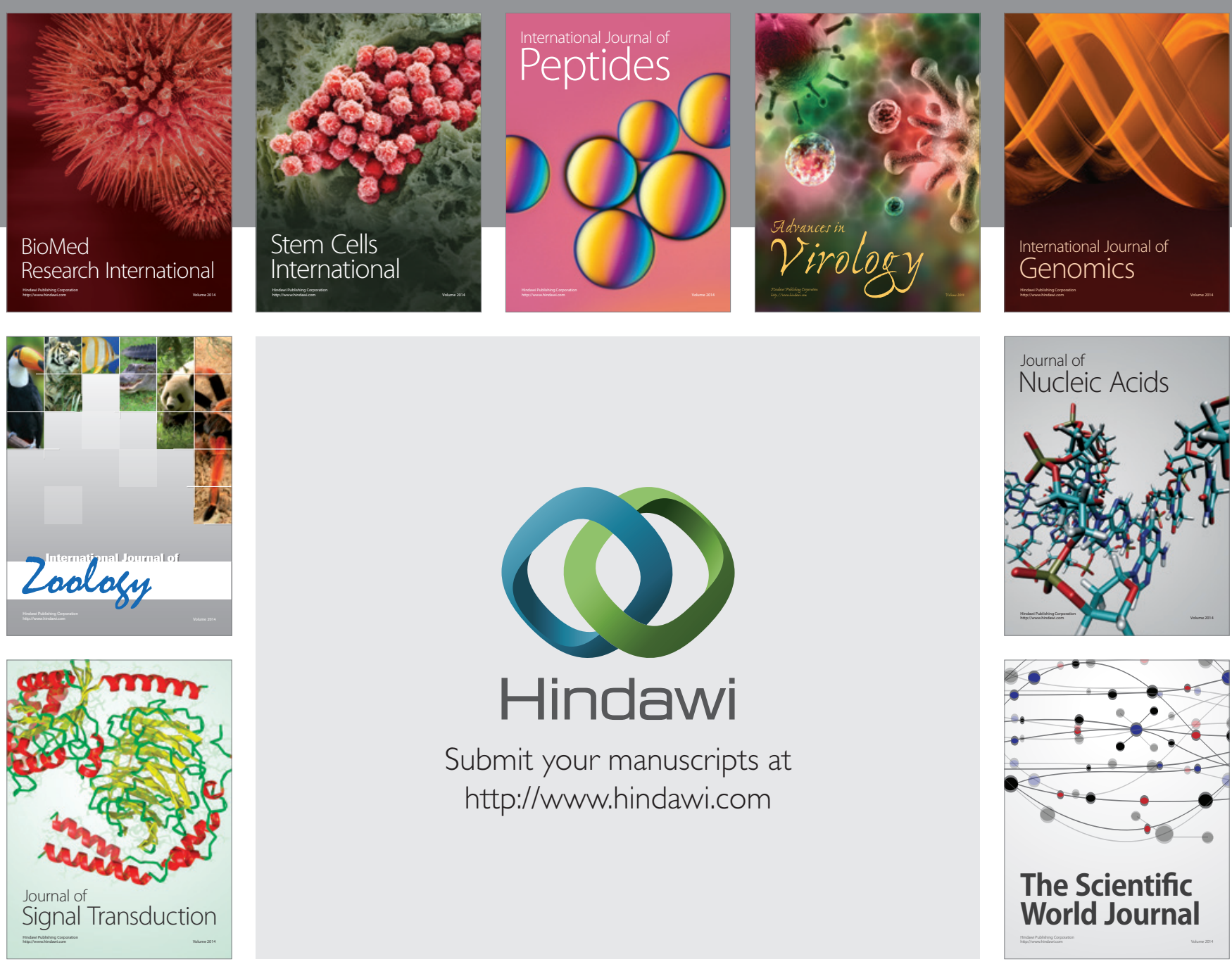

Submit your manuscripts at

http://www.hindawi.com
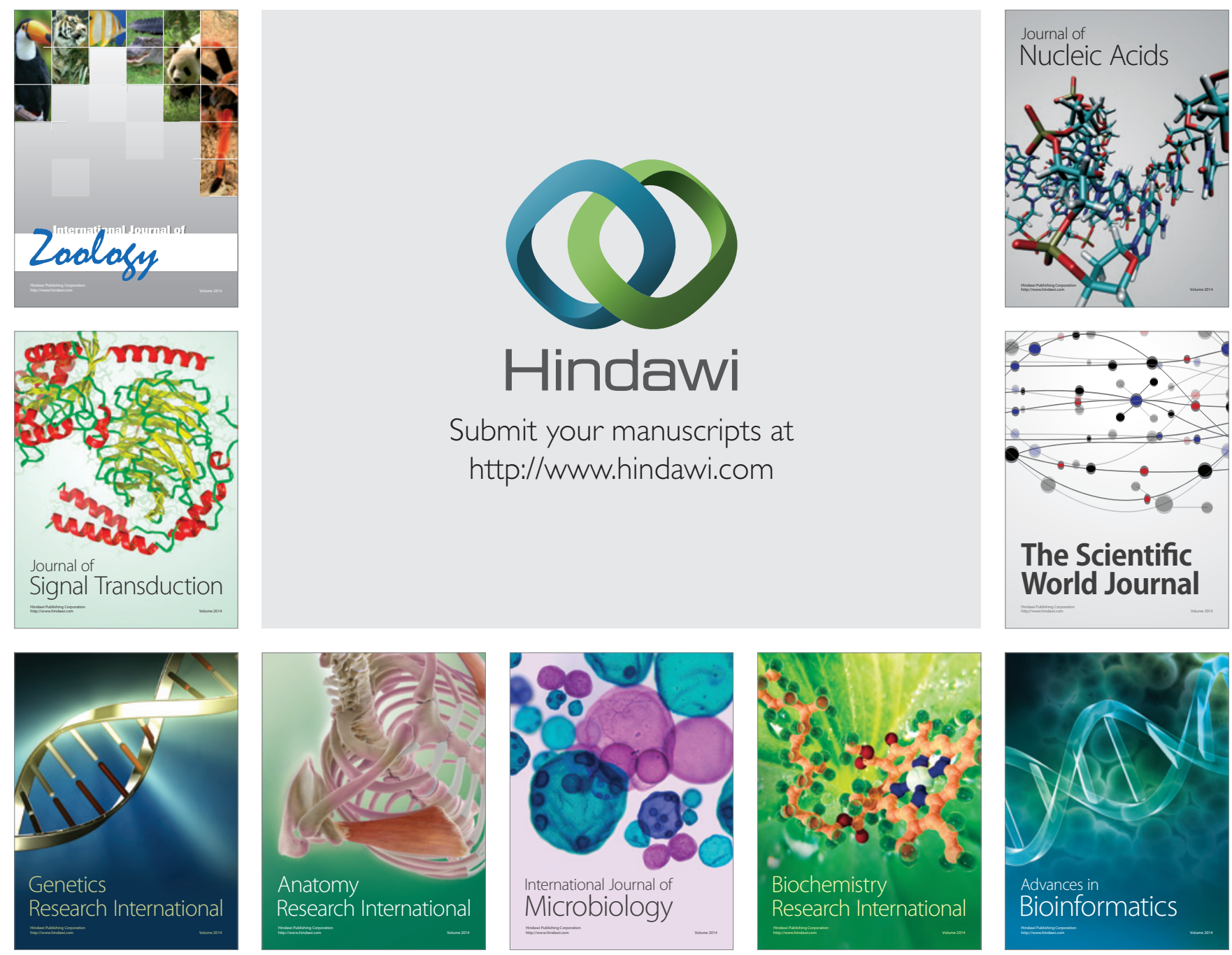

The Scientific World Journal
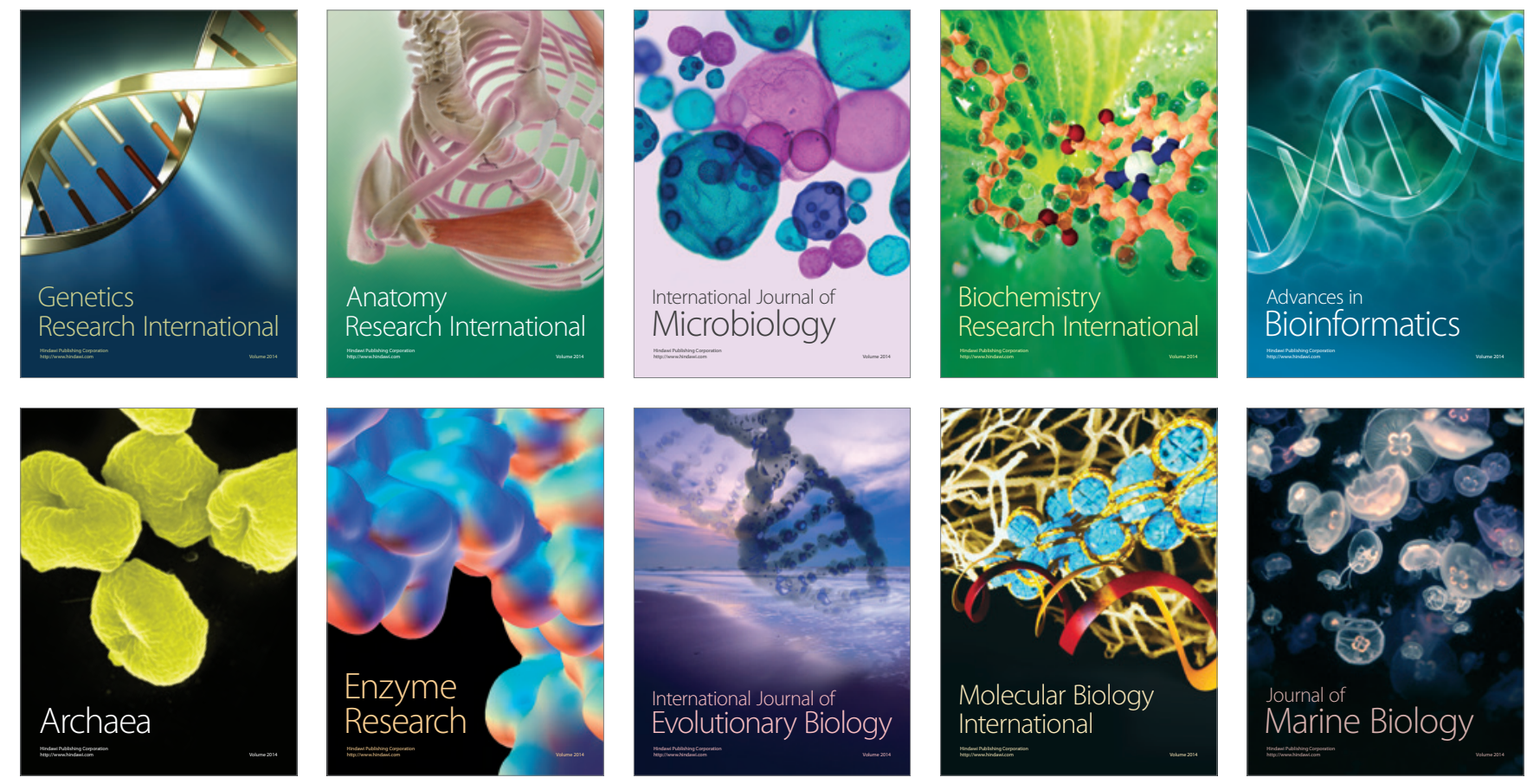